\title{
Comparison Study of Pile Foundation Using Eurocode 7 and Working Stress Design Approach
}

\author{
Abdelazim Makki Ibrahim ${ }^{\mathrm{a}, \mathrm{b}}$, Abubaker Atnisha ${ }^{\mathrm{b}}$, Ibrahim Malik ${ }^{\mathrm{a}}$ \\ a Al Neelain University-Sudan \\ b Technische Universität Bergakademie Freiberg, Germany
}

\begin{abstract}
Working Stress Design Approach (WSDA) has been used extensively to design Footing, Raft and Pile foundations with a global safety factor. A new design concept, Limit State Design Approaches (LSDA), following the Eurocode 7 has become popular in recent years. A comparison study between a working stress design approach with a factor of safety equal to two and the Ultimate Limit State (ULS) using Eurocode 7 design approaches with Serviceability Limit State verification (SLS) is done to evaluate the most economic design approach. This is done by calculating the number of piles to support a building of a characteristic vertical permanent load of $60 \mathrm{MN}$ and a characteristic vertical variable load of $20 \mathrm{MN}$ on $18 \mathrm{~m}$ bored piles with a diameter of $0.5 \mathrm{~m}$ founded on a multi-layer system of silty clay and silty sand and spaced at 3 meter centres. A simulation of three pile load tests using Finite Element Method PLAXIS Software were used in this study to determine the characteristic value of pile resistance and demonstrate pile foundation design using static pile load tests following the Eurocode7.
\end{abstract}

Keywords: - Pile Foundation, Eurocode 7, PLAXIS software

\section{INTRODUCTION}

Many researchers have studied the design of Footing, Raft and Pile foundation using the design concept of Limit State Design Approaches (LSDA) following the Eurocode 7. Useful information about Eurocode 7 can be found in the publications of Bowles JE (1984), Bauduin (2002), Orr (2010) and Ibrahim (2013). According to pREN 1997-1 (2001) the pile foundation shall be based on one of the following approaches:

1. The result of static load tests, which have been demonstrated, by means of calculations or otherwise, to be consistent with other relevant experiences.

2. Empirical or analytical calculation methods whose validity has been demonstrated by static load tests in comparable situations.

3. The result of dynamic load tests whose validity has been demonstrated by static load tests in comparable situations

4. The observed performance of a comparable pile foundation, provided that this approach is supported by the results of site investigations and ground testings.

\section{LIMIT STATE DESIGN}

The code also states that the design shall demonstrate that exceeding the following limit states is sufficiently improbable:

1. Ultimate limit states of compressive or tensile resistance failure of a single pile

2. Ultimate limit states of compressive or tensile resistance failure of the pile foundation as a whole

3. Ultimate limit states of collapse or severe damage to supported structure caused by excessive displacement or differential displacement of the pile foundation

4. Serviceability limit states in the supported structure caused by displacement of the pile

\section{THE STUDY AREA AND SOIL PROFILE}

The study area is a part of Khartoum state-Sudan. Khartoum is the capital of the Sudan and it is a site of many projects and concrete buildings are taking place. The subsurface soil in the study area is known by its low bearing capacity, excessive differential settlement and groundwater fluctuation.

Three boreholes were drilled to get soil samples for laboratory works. The boreholes revealed existence of alternating layers of very stiff low to high plasticity silty clays (CL to $\mathrm{CH}$ ) and very stiff low to high plasticity silts (ML to MH) in the upper 17 meters. This is underlain by a medium dense silty sand (SM or SP-SM) layer extending down to 25 meters and this layer overlays a very dense sand silt layer extending to 33 meters in depth. The alternating layers of weak mud-stone and weak sand stone extends down to the bottom of the boreholes at about 45 meters. These weak mud-stones and weak sandstones are belonging to the Omdurman formation which 
is extended to deepest depth. Data from the various exploration methods were used as a basis for typical sections to illustrate the more significant geological conditions. The objectives are to illustrate clearly the problems of the geologic environment influencing design and construction. Three dimensional models are plotted to help for sites with complex geology, Figure 1 .

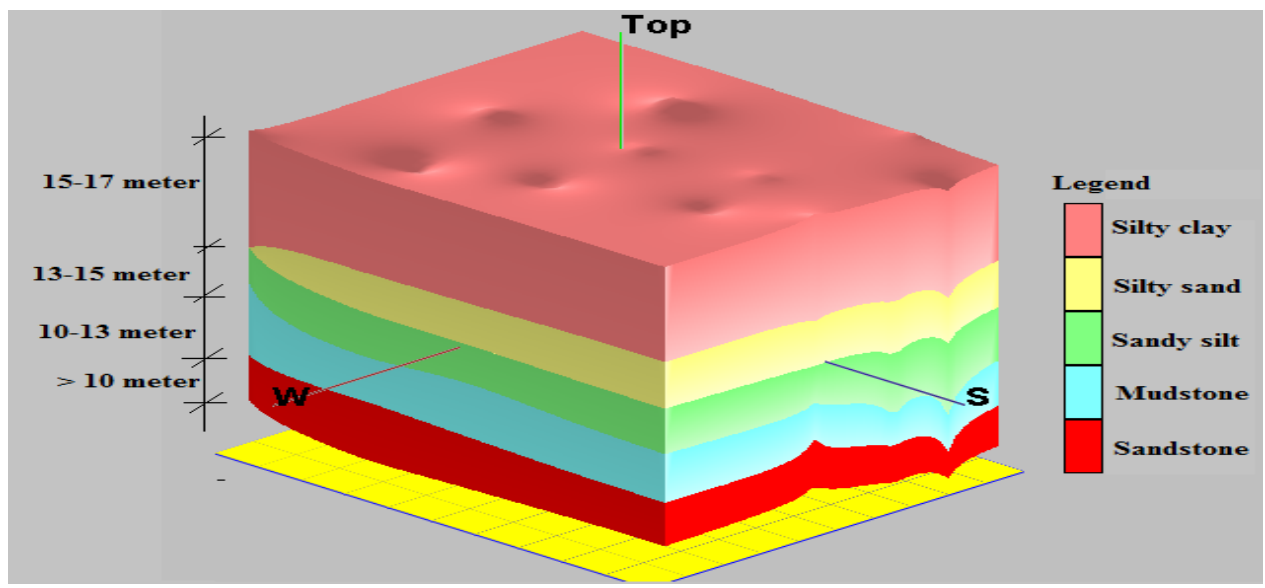

Figure 1: Three Dimensional Model for Subsurface Soil in the Study Area

IV. FINITE ELEMENT METHOD

Finite element techniques have become popular in recent years in the field of foundation engineering. To date, a variety of finite element computer programs have been developed with a number of useful facilities to suit different needs (E.Y. N OH et al., 2011) . The method is only an approximation, but extremely complex problems can be solved quickly by using the computer. The finite element method is commonly used to simulate environmental conditions and observe the resultant behavior. Simulation conditions can be forces or pressures, the resultant behavior would be the deflection and the stress or strain. The basic concept of the FEM is to break up the structure to a small volume known as a finite element. The element has size, density and stiffness and can deform similarly to real live scenarios when subjected to force. For each finite element, an equation is developed specifically and a description is made detailing how the finite element deformed from the force application. Adding all the finite elements together can simulate how the interior structure can deform when force is applied (Brinkgreve et al,2007). The elements have nodes on themselves to connect other elements together to transmit the loads; general speaking, the more finite elements given to the body the closer the approximation will be to real live. Load and fixtures are concepts to apply forces and pressures on the holding area of the model.

\section{SOIL MODEL}

Silty clay and silty sand layers are modeled using the Mohr-Coulomb model, which involves five input parameters, i.e, $E$ and $v$ for soil elasticity; friction angle $(\varphi)$ and cohesion (c) for soil plasticity and $\psi$ as an angle of dilatany. Even this model represents a ' first-order' approximation, and it is recommended to use for the first analysis of the problem. For each layer one estimates a constant average stiffness. Due to this constant stiffness, computations tend to be relatively fast so one obtains a first estimate of deformation relatively quickly (Plaxis, 2011). The geotechnical properties of Silty clay and Silty sand are shown in Table 1.

Table 1: Material properties of the soil

\begin{tabular}{|c|c|c|c|c|}
\hline Parameter & Name & Silty clay & Silty sand & Unit \\
\hline \multicolumn{5}{|l|}{ General } \\
\hline Material model & Model & Mohr-Coulomb & Mohr-Coulomb & - \\
\hline Drainage type & Type & Undrained & Drained & - \\
\hline Unit weight above phreatic level & $\gamma_{\text {unsat }}$ & 16 & 18 & $k N / m^{3}$ \\
\hline Unit weight below phreatic level & $\gamma_{\text {sat }}$ & 17 & 20 & $\mathrm{kN} / \mathrm{m}^{3}$ \\
\hline \multicolumn{5}{|l|}{ Parameters } \\
\hline Young's modulus & $E^{\prime}$ & $1.3 .10^{4}$ & $2.5 .10^{4}$ & $\mathrm{kN} / \mathrm{m}^{2}$ \\
\hline Poisson's ratio & $v$ & 0.34 & 0.3 & - \\
\hline Cohesion & $c$ & 45 & 5 & $k N / m^{2}$ \\
\hline Friction angle & $\phi$ & 5 & 30 & $o$ \\
\hline
\end{tabular}


VI.

PILE MODEL

The geometrical and size model was drawn sufficiently large to eliminate influencing boundaries on the results. The piles were modeled with respect to the Linear Elastic Model This model represents Hooke's law of isotropic linear elasticity. The model involves two elastic stiffness parameters, i.e. Young's modulus, E, and Poisson's ratio, $v$. The linear elastic model is seldom used to simulate soil behavior. It is primarily used for stiff massive structural systems installed in the soil, such as the test piles in this paper.

Driven and bored piles, with a pile diameter of $\mathrm{D}=0.5 \mathrm{~m}$ and a length $=18 \mathrm{~m}$ was used in this study. The building supported by the piles does not have the capacity to transfer the load from weak to strong piles. The parameters of the pile have been taken from the literature. Values were used in driven pile modeling and are shown in Table 2. Table. The soil model, embedded pile and generated mesh are shown in Figure 2.

Table 2. Material properties of embedded pile

\begin{tabular}{|l|c|l|l|}
\hline Parameter & Name & Pile foundation & Unit \\
\hline Young's modulus & $E$ & $3.10^{7}$ & $\mathrm{kN} / \mathrm{m}^{2}$ \\
\hline Unit weight & $\gamma$ & 6.0 & $\mathrm{kN} / \mathrm{m}^{3}$ \\
\hline Pile type & - & predefined & - \\
\hline Predefined pile type & - & Massive circular & - \\
\hline Diameter & Diameter & 0.5 & $\mathrm{~m}$ \\
\hline Skin resistance & Type & Linear & - \\
\hline $\begin{array}{l}\text { Maximum torsion allowed at the top of the embedded } \\
\text { pile }\end{array}$ & $T_{\text {top } \text { max }}$ & 200 & $\mathrm{kN} / \mathrm{m}$ \\
\hline $\begin{array}{l}\text { Maximum torsion allowed at the bottom of the } \\
\text { embedded pile }\end{array}$ & $T_{\text {bot,max }}$ & 500 & $\mathrm{kN} / \mathrm{m}$ \\
\hline Base resistance & $F_{\max }$ & $1.5 .10^{4}$ & $\mathrm{kN}$ \\
\hline
\end{tabular}

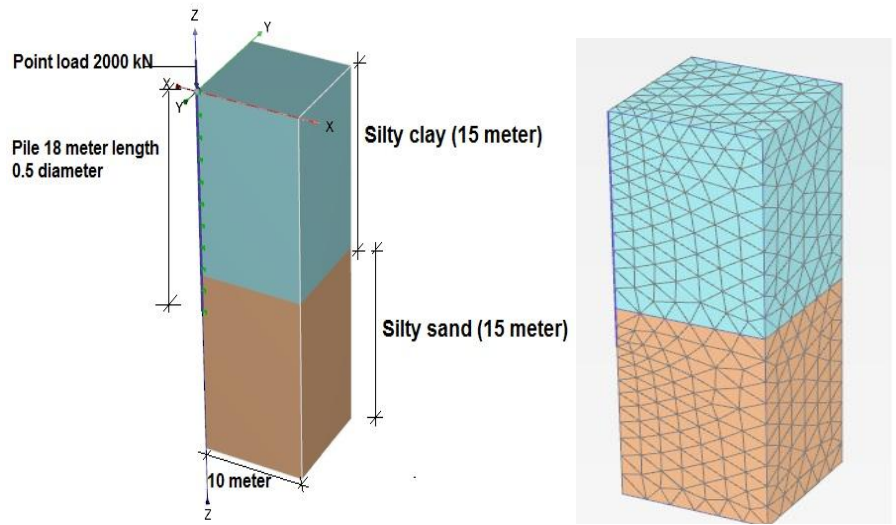

Figure 2: Soil Model, Embedded Pile and Generated Mesh

VII. CHARACTERISTICS VALUE OF THE PILE RESISTANCE FROM STATIC LOAD TESTS

To determine soil resistance, three pile load tests were simulated using PLAXIS 3D Software. Piles were loaded beyond a settlement of $0.1 \mathrm{D}=50 \mathrm{~mm}$ to give the limit load a typical result from such a test. These are shown in Fig 3. 


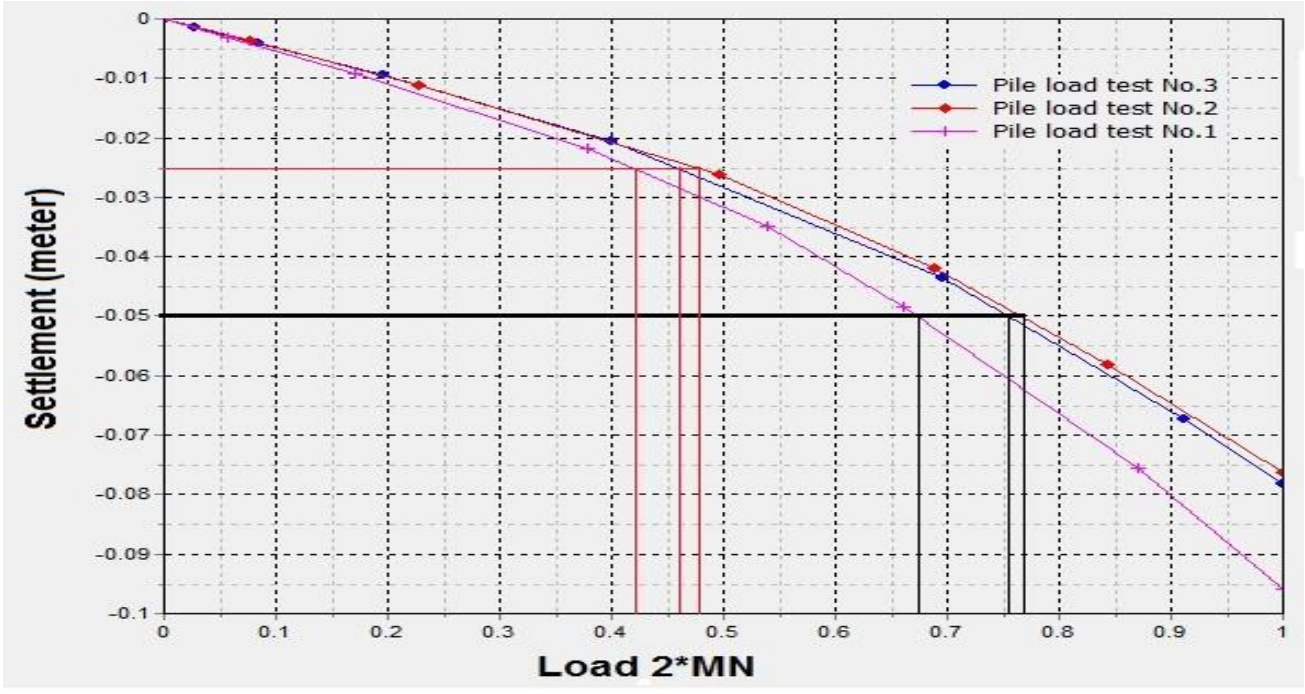

Figure 3: Load Transfer Settlement Relationship

Three (Pile load tests) were conducted to determine soil resistance. The results of ultimate resistance are shown in Table 3.

Table 3. Calculation Results of Predicted Compressive Resistance at Each Pile Load Test

\begin{tabular}{|l|ll|}
\hline Pile Load Test & \multicolumn{1}{c|}{$q_{u}(k N)$} \\
\hline 1 & 1344 & \\
\hline 2 & 1550 & \\
\hline 3 & 1520 & \\
\hline
\end{tabular}

The characteristic value of the pile compressive resistance $R_{\mathrm{c}, \mathrm{k}}$ was obtained from the following equation according to EC7.

$R_{c, k}=\min \left\{\frac{\left(R_{c ; m}\right) \text { mean }}{\xi_{1}}, \frac{\left(R_{c ; m}\right) \min }{\xi 2}\right\}:$

$\left(R_{c ; m}\right)$ mean: the mean value of the measured pile resistances;

$\left(R_{c ; m}\right)$ min: the lowest measured pile compressive resistance;

where $\xi_{1}$ and $\xi_{2}$ are correlation factors related to the number of piles tested and are applied to the mean $\left(R_{c ; m}\right)$ mean and the lowest $\left(R_{c ; m}\right)$ min of $R_{c ; m}$ respectively.

Table 4 indicates values of $\xi 1$ and $\xi 2$ proposed in prEN 1997-1: 2001(E);

Table 4. Values of $\xi 1$ and $\xi 2$ for Ground Test Results

\begin{tabular}{|l|l|l|l|l|l|}
\hline Number of Tested Profiles & 1 & 2 & 3 & 4 & $\geq 5$ \\
\hline$\xi_{1}$ applied to the mean & 1.40 & 1.3 & 1.2 & 1.10 & 1.00 \\
\hline$\xi_{2}$, applied to the lowest & 1.40 & 1.2 & 1.05 & 1.00 & 1.00 \\
\hline
\end{tabular}

From Table 3, for $\mathrm{n}=3$ pile load tests: $\xi 1=1.20$ and $\xi 2=1.05$. The mean value out of three test results is 1471.3 $k N$ and the minimum value is $1344 \mathrm{kN}$. Applying the criteria recommended by EC 7, the factor $\xi 1=1.2$ will be applied to the mean value and $\xi_{2}=1.05$ is applied to the lowest value. The following results are obtained (mean, $1471.3 / 1.2=1226.1 \mathrm{kN}$ and the lowest, $1344 / 1.05=1280 \mathrm{kN}$.

According to the EC 7 procedure, the mean value (1226.1) will govern the design and if the stiffness of the structure is accounted (Ibrahim, 2012), the mean value 1226.1 may be multiplied by the coefficient 1.1 and the characteristic value becomes $1226.1 * 1.1=1348.71 \mathrm{kN}$.

\section{PILE DESIGN VALUE}

The design value of pile will be obtained from the characteristic value using the following equation: $R_{\mathrm{c}, \mathrm{d}}=\frac{R_{c k}}{\gamma_{t}}$

Where; 
$R_{\mathrm{c}, \mathrm{d}}$ is design value of pile resistance

$R_{c k}$ is characteristic value of pile resistance

$\gamma_{t}$ is partial factors as proposed in prENV 1997-1:2001(E) are indicated in Table 5.

Table 5 shows the recommended values for $\gamma_{b}, \gamma_{s}, \gamma_{t}$ (from Tables A.6, A.7, A.8 of Annex A in EN 1997-1 taken from Frank 2008)

Table 3. Partial Factors for Approaches 1 and 2 for Different Types of Piles According to prEN 1997-1:2001(E)

\begin{tabular}{|l|c|c|c|c|c|c|l|l|}
\hline & \multicolumn{3}{|l|}{$\begin{array}{l}\text { Design Approach 1 } \\
\text { Combination 2 (DA1-2) }\end{array}$} & \multicolumn{2}{l|}{$\begin{array}{l}\text { Design Approach 1 } \\
\text { Combination 1 (DA1- } \\
\text { 1) }\end{array}$} & $\begin{array}{l}\text { Design } \\
\text { Approach 2 2 } \\
\text { (DA2) }\end{array}$ & $\begin{array}{l}\text { Design } \\
\text { Approach 3 } \\
\text { (DA3) }\end{array}$ \\
\hline Type of Pile & $\gamma_{b}$ & $\gamma_{s}$ & $\gamma_{t}$ & $\gamma_{b}$ & $\gamma_{s}$ & $\gamma_{t}$ & $\gamma_{b}=\gamma_{s}=\gamma_{t}$ & $\gamma_{b}=\gamma_{s}=\gamma_{t}$ \\
\hline Driven Piles & 1.3 & 1.30 & 1.30 & 1.0 & 1.0 & 1.0 & 1.10 & 1.0 \\
Bored Piles & 1.3 & 1.60 & 1.45 & 1.25 & 1.0 & 1.15 & 1.10 & 1.0 \\
Continuous & 1.3 & 1.45 & 1.35 & 1.10 & 1.0 & 1.10 & 1.10 & 1.0 \\
Flight Auger & & & & & & & & \\
\hline
\end{tabular}

The results of pile design value for the driven pile using EC 7 Approach 1 Combination 1 and Approach 1 Combination 2 and Approach 2 is shown in Table 6.

Table 6. Design Values for Driven Piles using EC7

\begin{tabular}{|l|l|}
\hline Design Approach & Pile Design Value $k N$ \\
\hline (DA1-1) & 1348.71 \\
\hline (DA1-2) & 1037.5 \\
\hline (DA2) & 1226.1 \\
\hline
\end{tabular}

\section{CHARACTERISTICS VALUE OF ACTIONS}

A building of a characteristic vertical permanent load of $60 \mathrm{MN}$ and characteristic vertical variable load of 20 $\mathrm{MN}$ founded on silty clay and silty sand supported by $0.5 \mathrm{~m}$ daimeter and $18 \mathrm{~m}$ piles is used in this study. The purpose of the study is to find the total settlement and number of piles needed to support this load using different Eurocode 7 approaches.

\section{Design Values of Actions}

Partial values of actions recommended by EN 1997-1 form Table A.3 of Annex A are shown in Table 7

Table 7. Recommended Values for $\gamma_{F}$ on Actions or Effect of Actions (EN 1997-1 Table A.3 of Annex A)

\begin{tabular}{|l|l|l|l|l|}
\hline Action & (DA1-1) & $(\mathrm{DA} 1-2)$ & $(\mathrm{DA} 2)$ \\
\hline \multirow{3}{*}{ Permanent } & Unfavorable & 1.35 & 1.0 & 1.23 \\
\cline { 2 - 5 } & Favorable & 1.0 & 1.0 & 1.0 \\
\hline \multirow{2}{*}{ Variable } & Unfavorable & 1.5 & 1.3 & 1.5 \\
\cline { 2 - 5 } & Favorable & 0 & 0 & 0 \\
\hline
\end{tabular}

For (DA1-1) Design Value of action $\left(V_{d}\right)=1.35\left(G_{k}\right)+1.5\left(Q_{k}\right)=1.35 * 60000+1.5 * 2000=111000 \mathrm{kN}$

For (DA1-2) Design Value of action $\left(V_{d}\right)=1\left(G_{k}\right)+1.3\left(Q_{k}\right)=1 * 60000+1.3 * 20000=86000 \mathrm{kN}$

For (DA2) Design Value of action $\left(V_{d}\right)=1.35\left(G_{k}\right)+1.5\left(Q_{k}\right)=1.35 * 60000+1.5 * 2000=111000 \mathrm{kN}$

Table 8 shows the results of a number of piles for each design approach.

Table 8. Number of Driven Piles for ULS Design

\begin{tabular}{|l|l|l|}
\hline Type of Code & Load Design Value kN & Numbers of Piles \\
\hline DA1_1 & 111000 & $111000 / 1348.71 \approx 83$ \\
\hline DA1_2 & 86000 & $86000 / 1037.5 \approx 83$ \\
\hline DA2 & 111000 & $111000 / 1226.1 \approx 91$ \\
\hline
\end{tabular}

\section{Determination of the Number of Piles if Bored Piles are use in the Foundation}

Following the same procedure used to determine the number of driven piles, with the only difference of partial factors applying to the resistance according to Table 3 . The design values of different design approaches of bored piles are shown in Table 9. 
Table 9. Design Values for Bored Piles using EC7

\begin{tabular}{|l|l|}
\hline Design Approach & Pile Design Value $k N$ \\
\hline (DA1-1) & 1172.8 \\
\hline (DA1-2) & 930.3 \\
\hline (DA2) & 1226.1 \\
\hline
\end{tabular}

The numbers of bored piles are shown in Table 10 .

Table 10. Number of Bored Piles for ULS Design

\begin{tabular}{|l|l|l|}
\hline Type of Code & Load Design Value kN & Numbers of Piles \\
\hline DA1_1 & 111000 & $111000 / 1172.8 \approx 95$ \\
\hline DA1_2 & 86000 & $86000 / 930.3 \approx 93$ \\
\hline DA2 & 111000 & $111000 / 1226.1 \approx 91$ \\
\hline
\end{tabular}

\section{Determination of the Number of Piles, Serviceability Limit States (SLS)}

For SLS, the design load is equal to the addition of the Permanent vertical load Gk $=60,000 \mathrm{kN}$ and the Variable vertical load $\mathrm{Qk}=20,000 \mathrm{kN}=80,000 \mathrm{kN}$

The design resistance for SLS for allowable settlement $=25 \mathrm{~mm}$, and is the same as the procedure followed for ULS. The partial factor $\xi 1$ applied to the mean is 1.2, and partial factor $\xi 1$ applied to the lowest is 1.05.

Taking the allowable settlement equal to $25 \mathrm{~mm}$, and from Figure 1, the mean value out of three test results is 903.3 $\mathrm{kN}$ and the minimum value is $840 \mathrm{kN}$. Applying the criteria recommended by EC 7, the factor $\xi 1=1.2$ will be applied to the minimum value and $\xi 2=1.05$ applied to the mean value. The following result is obtained minimum, 9.03/1.2 $=752.8 \mathrm{kN}$ and the mean, 840/1.05 $=800 \mathrm{kN}$.

According to EC 7 procedure the mean value will govern the design.

The number of piles $=80000 / 752.8 \approx 107$ piles

\section{Determination the Number of Piles using British Standard (BS 8004 code)}

Using the working stress design approach with a factor of safety equal to 2 , the number of piles supporting the buildng maybe determined as follows:

1. Determine the mean limit bearing resistance beyond the settlement equal $50 \mathrm{~mm}$ from Fig. 3

2. Divided the mean bearing resistance by a safety factor equal to 2

3. Divided the load of the building by the bearing resistance from step 2 to find the number of piles

From Table 1, the mean predicted compressive resistance is $1.4713 \mathrm{e}+003$, by dividing this number by a factor of safety equal to 2 , the allowable bearing resistance $=735.6500$. Thus the number of piles $=80000 / 735.6500=$ $108.7474 \approx 109$ piles

\section{DISCUSSION OF THE RESULT}

As it is seen in Figure 4 and Figure 5:

- $\quad$ For the same load the number of bored piles is more than the number of driven piles

- For driven piles the Eurocode 7-DA2 is more conservative than DA1-1 and DA1-2

- No difference of number of piles for bored and driven piles if DA2 is used

- The Serviceability Limit State governed the design

- The number of piles using stress design approach with a factor of safety equal to 2 is more than the number of piles of SLS which governs the Eurocode 7 design 


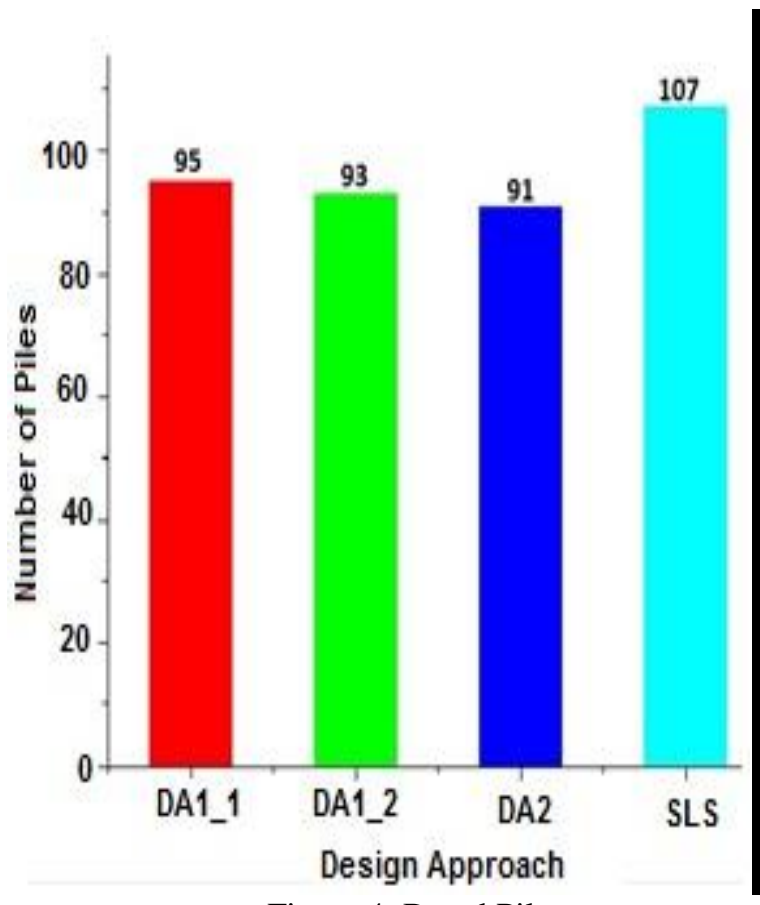

Figure 4: Bored Piles

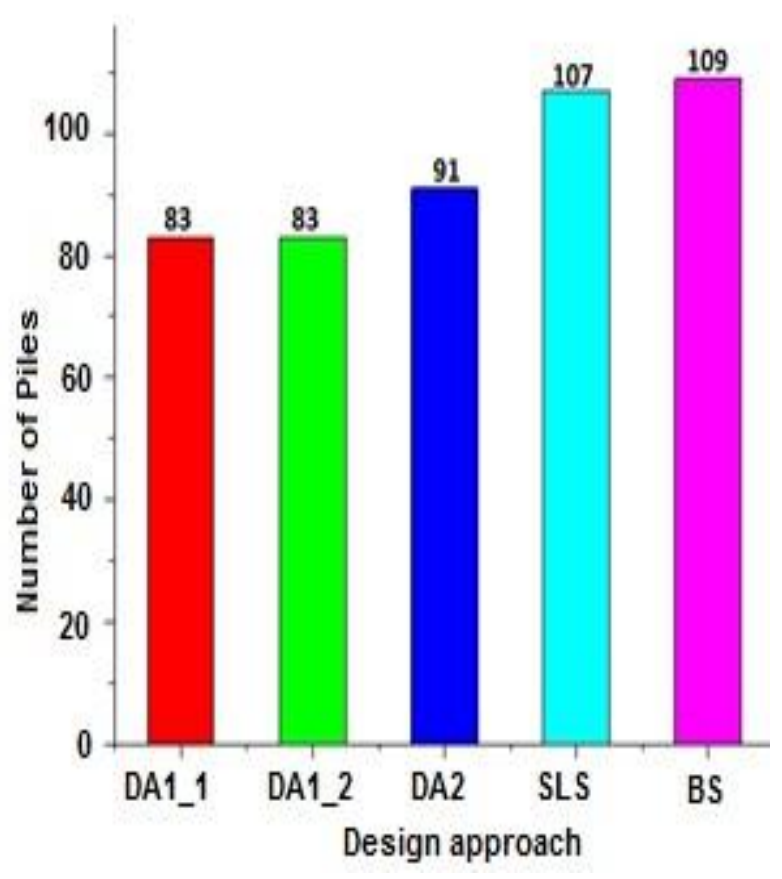

Figure 5: Driven Piles

XI.

CONCLUSION

In ultimate limit state design approach, safety factors are applied individually to materials and load characteristics. This precise analysis of the material prosperities and accurate load determination leads to lower construction costs of the structure with a very low probability of a failure occurrence. On the other hand, for working stress design approach the stresses on structure components are calculated based on elasticity theory and they are designed in such a way so that certain permissible values are not exceeded. Even the probability of failure under stress design approach is less than the Ultimate Limit State Design Approach, however the economical design cannot be achieved

\section{REFERENCES}

[1] Bauduin, C. B., (2002). Design of axially loaded compression piles according to Euro Code 7. Proceedings - Ninth International Conference on Piling and Deep Foundations, 2002, Nice, France, (DFI).

[2] Bowles, J. E., (1984). Physical and Geotechnical properties of soil. McGraw-Hill book. Japan.

[3] Brinkgreve, R.B.J. and Swolfs, W.M. (eds.) (2007) PLAXIS 3D Foundation version 2 User Manual, Plaxis bv, The Netherlands

[4] OH, E.Y. N, HUANG, M., SURARAK, C., Adamec, R and . BALASURBAMANIAM , A. S., (2011). Finite element modeling in piled raft foundation in sand. Geotechnical Engineering Journal of the SEAGS \& AGSSEA Vol 42 No. 2

[5] Ibrahim, A., Ibrahim, M., Omar, A., (2013). Pile design using Eurocode 7: A case study. Journal of Civil Engineering and Construction Technology Vol. 4(3), pp. 70-80, March 2013

[6] Orr, T. L. L., Denys, B., (2010). The concepts of Eurocode 7 for harmonized geotechnical design in Europe. Politechnika Wrocławska Studia Doktoranckie.

[7] PLAXIS. (2011). Plaxis user manual, Delft University of Technology \& Plaxis bv The Netherlands.

[8] pREN 1997-1., (2001) Geotechnical Design - Part 1: General Rules. European Committee for Standardization, Brussels. 